\title{
Status of the NGNP Graphite Creep \\ Experiments AGC-1 and AGC-2 Irradiated in the Advanced Test Reactor
}

\author{
HTR 2012
}

\author{
S. Blaine Grover
}

U.S. Department of Energy

National Laboratory

operated by

Battelle Energy Alliance

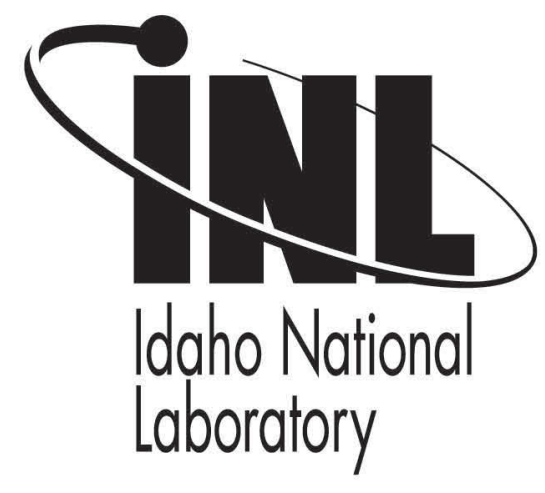

This is a preprint of a paper intended for publication in a journal or proceedings. Since changes may be made before publication, this preprint should not be cited or reproduced without permission of the author. This document was prepared as an account of work sponsored by an agency of the United States Government. Neither the United States Government nor any agency thereof, or any of their employees, makes any warranty, expressed or implied, or assumes any legal liability or responsibility for any third party's use, or the results of such use, of any information, apparatus, product or process disclosed in this report, or represents that its use by such third party would not infringe privately owned rights. The views expressed in this paper are not necessarily those of the United States Government or the sponsoring agency. 


\title{
Status of the NGNP Graphite Creep Experiments AGC-1 and AGC-2 Irradiated in the Advanced Test Reactor
}

\author{
S. Blaine Grover \\ Idaho National Laboratory \\ P.O. Box 1625, Idaho Falls, Idaho, 83415, United States of America \\ phone: 208-526-4489,Blaine.Grover@inl.gov
}

\begin{abstract}
The United States Department of Energy's Next Generation Nuclear Plant (NGNP) Program will be irradiating six nuclear graphite creep experiments in the Advanced Test Reactor (ATR) located at the Idaho National Laboratory (INL). The graphite experiments will be irradiated over the next six to eight years to support development of a graphite irradiation performance data base on the new nuclear grade graphites now available for use in high temperature gas reactors. The goals of the irradiation experiments are to obtain irradiation performance data, including irradiation creep, at different temperatures and loading conditions to support design of the Next Generation Nuclear Plant (NGNP) Very High Temperature Gas Reactor, as well as other future gas reactors. The experiments will each consist of a single capsule that will contain six peripheral stacks of graphite specimens, with half of the graphite specimens in each stack under a compressive load, while the other half of the specimens will not be subjected to a compressive load during irradiation. The six peripheral stacks will have three different compressive loads applied to the top half of three diametrically opposite pairs of specimen stacks, while a seventh stack will not have a compressive load. The specimens will be irradiated in an inert sweep gas atmosphere with on-line temperature and compressive load monitoring and control. There will also be sampling the sweep gas effluent to determine if any oxidation or off-gassing of the specimens occurs during irradiation of the experiment.
\end{abstract}

The first experiment, AGC-1, started its irradiation in September 2009, and the irradiation was completed in January 2011. The second experiment, AGC-2, started its irradiation in April 2011 and completed its irradiation in May 2012. This paper briefly discusses the design of the experiment and control systems, and then presents the irradiation results for each experiment to date.

\section{INTRODUCTION}

The United States Department of Energy's Next Generation Nuclear Plant (NGNP) Program will irradiate six gas reactor graphite creep experiments in the Advanced Test Reactor (ATR) located at the Idaho National Laboratory (INL). The graphite irradiations are being performed over the next six to eight years to support development of the next generation reactors in the United States.

The historical nuclear grade graphites are no longer available due to depletion of the feedstock material used in their manufacture. However, new nuclear grade graphites have been developed to replace the historical graphites for use in the nuclear industry. The goals of the irradiation experiments (designated the Advanced Graphite Capsule [AGC] series) are to obtain irradiation performance data on the new nuclear grade graphites at different temperatures and compressive load conditions to support design of the NGNP Very High Temperature Gas Reactor (VHTR), as well as other future high temperature gas reactors. The graphite specimens are being irradiated in an inert sweep gas atmosphere 
with on-line temperature and compressive load monitoring and control. Grab samples of the sweep gas effluent are analyzed to determine if oxidation or off-gassing of the specimens occurs during irradiation of the experiment.

The design for the first experiment (AGC-1) was completed in September 2008, and the experimental test train and support systems were completed in early 2009. The irradiation of AGC-1 was started in September 2009 and completed in January 2011. The design of the second experiment (AGC-2) was completed in August 2010, and the experiment assembly was completed in February 2011. The support systems installed for AGC-1 are being used for all of the NGNP graphite irradiation experiments. The irradiation of AGC-2 was started in April 2011 and completed in May 2012. The design of the experiment and control systems will be briefly discussed, but a more detailed description can be found in Reference [1]. The preliminary irradiation results for AGC-1 and AGC-2 will also be presented.

\section{EXPERIMENT CAPSULE}

Details of the experimental hardware (or test train) located within the reactor vessel and the irradiation specimens are discussed in the following subsections.

\section{II.A. Test Train}

The experiment test train consists of a capsule (the portion within ATR core), and an umbilical tube (termed a lead out) extending from the top of the capsule up through the top head of the ATR reactor. A horizontal cross-section of the experiment capsule at the top of the reactor core is shown in Figure 1.

The capsule portion of the test train is approximately $64 \mathrm{~mm}$ (2.5 inches) in diameter and $2.3 \mathrm{~m}$ (90 inches) in height, extending from approximately 0.9 meters (32 inches) below the 1.2 meter (48 inch) tall active ATR core to approximately 0.25 meters ( 9 inches) above the top of the core. The capsule contains seven separate stacks of graphite specimens. Six of the specimen stacks are arranged around the perimeter of the capsule, and the seventh stack is located in the center. The specimen stacks were numbered in clockwise direction around the perimeter of the capsule with stack 1 (initially) on the side of the capsule towards the ATR core and stack seven being in the center of the capsule. The top half of the six perimeter specimen stacks have a compressive load applied to them during irradiation to determine irradiation creep. The lower half of the perimeter stacks are not subjected to a compressive load in order to provide a benchmark for the loaded specimens. The seventh stack of specimens does not have a compressive load on any of its specimens during irradiation.

A graphite specimen holder surrounds and separates the seven specimen stacks and has features machined to accommodate the temperature control and compressive load control gas lines as well as the thermocouples for measuring temperature within the capsule. The graphite holder also provides the inner most boundary of two adjacent insulating gas jackets used for temperature control of the specimens during irradiation.

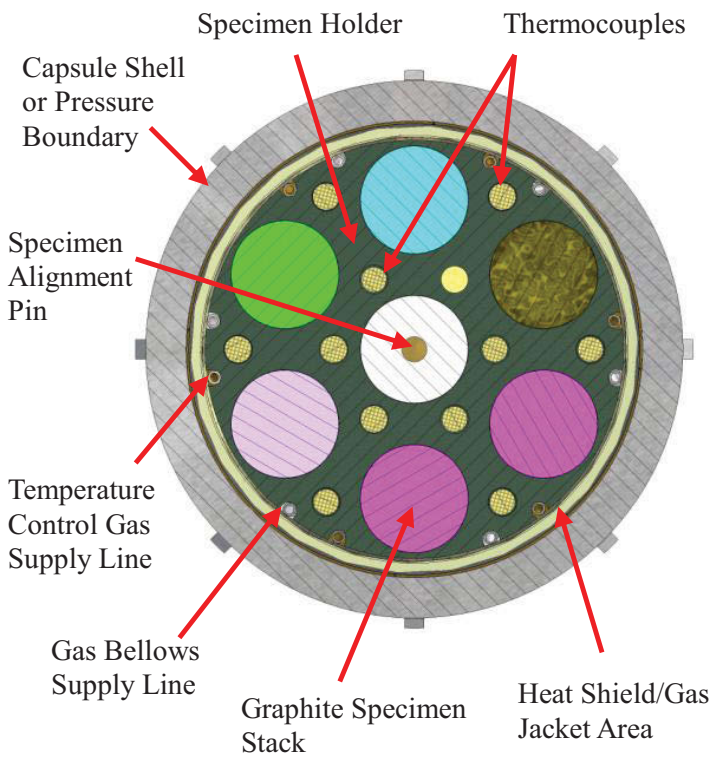

Fig. 1: AGC Capsule Horizontal Cross-Section

An inert sweep gas atmosphere surrounding the specimens during irradiation is used in conjunction with the gas jackets to maintain the desired temperatures in the specimens. The sweep gas enters the capsule in six temperature control gas lines. Four gas lines provide sweep gas to the graphite specimens and the specimen holder located inside of a radiation heat shield, and the other two gas lines provide sweep gas to the gas jacket between the radiation heat shield and the capsule pressure boundary. The flow from the six lines is distributed and directed to the appropriate section of the capsule in a plenum area located at the bottom of the specimen holder. 


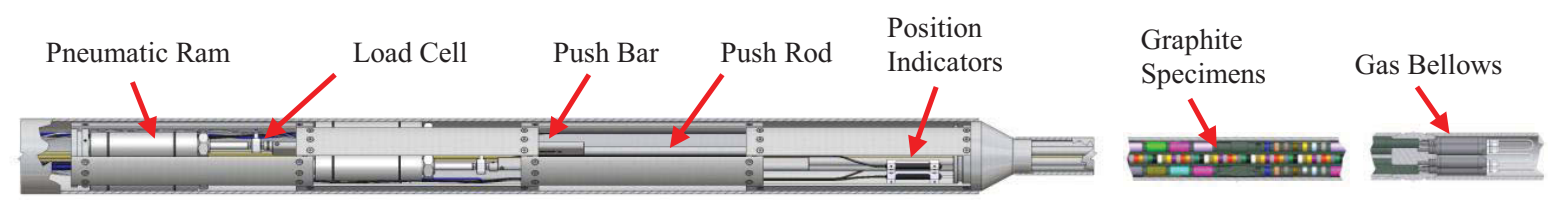

Fig. 2: AGC Test Train Vertical Section

In addition to the six temperature control gas lines, there are also six compressive load control gas lines that traverse through the core section to supply gas to a series of gas bellows located at the bottom of the test train that are part of the compressive load control system.

Twelve thermocouples are distributed across the graphite specimen holder and throughout its height to provide well characterized temperature indication of the holder. The temperature data from the holder is then used with the thermal analysis model to determine the temperatures within the graphite specimens. This approach was used primarily due to the graphite specimens relative movement during irradiation (e.g. irradiation damage, creep strain, etc.) that could possibly result in loss of contact between the graphite specimens and the thermocouples. However, measuring the graphite holder temperature also avoided having to dedicate some of the specimens to temperature measurement.

A vertical section of the test train in Figure 2 shows the smaller diameter capsule portion of the test train leading up to the larger diameter lead-out that composes the upper section of the test train. One of the primary functions of the lead-out portion of the test train is to house and protect the gas lines and thermocouple leads between the experiment capsule(s) and the reactor pressure vessel penetration.

At the reactor vessel penetration, the gas lines and thermocouple leads are connected to their facility counterparts in the monitoring, control and data collection systems. In the graphite creep experiments, the lead-out also houses a major portion of the test train compressive load control system components (e.g. pneumatic rams, load cells, push bars, etc.). The compressive force on the upper graphite specimens in the perimeter stacks is provided by the pneumatic rams located in the leadout portion of the test train. A piston located at the vertical center of the ATR core in each specimen stack rests on a ledge in the graphite specimen holder to resist the force from the rams and therefore place the specimens under a compressive load. A more detailed discussion of the compressive load control components shown in the test train and their functions is included in the compressive load control subsection of this paper.

The last major function of the lead-out is to vertically locate the experiment within the irradiation position in the ATR core, which was the south flux trap for AGC-1 and AGC-2 but will be the east flux trap for the later experiments. These positions are shown in Figure 3.

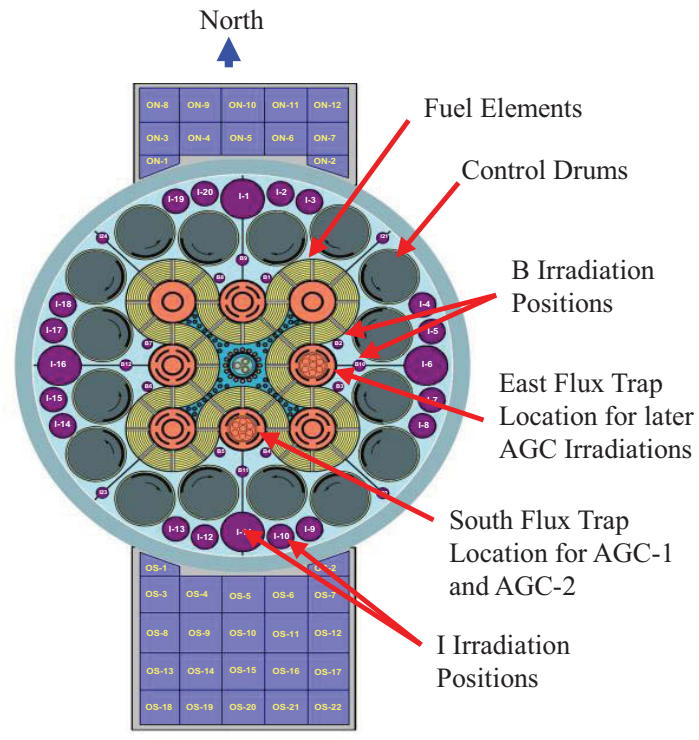

Fig. 3: ATR Core Cross-Section

A flux trap position (66 mm or 2.6 inch diameter) was chosen for the AGC irradiations due to its relatively high fast neutron flux rate and large size which permits a large number of graphite specimens in a single experiment to achieve relatively high fast neutron damage levels quickly.

\section{II.B. Irradiation Specimens}

There are two different sizes of graphite specimens. The large specimens are $12.3 \mathrm{~mm}(0.5$ inch) in diameter and $25 \mathrm{~mm}$ (1.0 inch) long. The short specimens are also $12.3 \mathrm{~mm}$ (0.5 inch) in 
diameter but only $6.4 \mathrm{~mm}$ (.25 inch) long. The experiment contains a selection of the large and small specimens from both the new nuclear grade graphites identified for use in both prismatic and pebble bed gas reactors as well as archive samples of historical graphites to provide a link to the historical graphite irradiation property database.

In AGC-1, the six perimeter stacks each contained 15 large compressively loaded specimens above core centerline and a combination of 14 large and 10 small specimens below core center that did not have a compressive load. The center stack contained 172 small specimens, all without a compressive load imposed upon them during irradiation. The quantities of the specimens in AGC2 were affected by two changes in the specimen stacks. First the addition of gamma heaters to provide enhanced temperature control reduced available space in all seven specimen stacks. However, the second change, removal of most of the specimen spacers with only a few remaining to house neutron flux monitors, increased the available space in the perimeter stacks. The number of specimens in each of the perimeter stacks was increased from 29 large and 14 small specimens in AGC-1 to 36 large and an average of 16 small specimens in AGC-2. The center stack only contained 170 small specimens in AGC-2 versus 172 in AGC-1.

Encapsulated neutron flux measurement wires are installed inside the alignment pins of the few strategically located graphite spacers. These spacers are located between specimens in the perimeter stacks to measure the specimen thermal and fast neutron fluences. The data from these wires will be used to verify the results of the as-run reactor physics analysis.

\section{CONTROL SYSTEMS}

The following subsections provide a brief description of the temperature and load control systems employed in the AGC experiments irradiations.

\section{III.A. Temperature Control System}

The temperature of the experiment is controlled by varying the mixture of two inert gases with different thermal conductivities in a small insulating gas jacket between the specimens and the experiment containment. Helium is always the high thermally conductive gas, and argon was selected for the insulating gas in this experiment series. Argon provides a nice wide temperature control band due to its relatively low thermal conductivity. It was selected for this experiment series to minimize the design changes needed between the different experiments irradiated at three different temperatures $\left(600,900\right.$, and $\left.1200{ }^{\circ} \mathrm{C}\right)$. This gas has been used quite extensively at the INL in the past for material (e.g. versus fuel) irradiations. However, it is normally not used for fuel experiments since quite often the temperature control exhaust gas is monitored for fission gases and the radiation from activated argon (e.g. Ar-41) can easily over shadow the radiation from the very low concentrations of fission gases.

The gas temperature control systems at ATR use computer controlled mass flow controllers to automatically blend the two inert gases based upon feedback from the experiment thermocouples. The mixture is controlled to provide the proper thermal conductivity in the insulating gas jacket to achieve and maintain the desired temperature(s) at the thermocouple location(s). In the AGC experiments, the temperature of the graphite specimen holder, which will be analytically coupled to the specimen temperatures, is measured and controlled to achieve and maintain the desired temperatures in the specimens. In order to minimize temperature changes and maintain the temperature as constant as possible, the control system provides a continuous sweep gas flow to through the capsule.

The control system conducts an automatic gas verification to assure the correct gases are connected to the supply ports in the system prior to allowing a new gas bottle to be placed into service. This verification prevents unplanned temperature excursions. Helium purges (to cool the experiment capsule) are under automatic control in the unlikely event that measurement or control of the capsule temperature is lost. Manual control capability is provided at the gas blending panels to provide helium purge in the event of a computer failure. The system will also automatically switch to helium purge on a power failure to the mass flow controllers.

The temperature measurements are taken by the twelve thermocouples in the experiment capsule, one of which is designated as the control thermocouple. In the event the control thermocouple fails open (as indicated by a significant increase in resistivity); temperature control of the capsule will automatically be switched over to the designated primary back-up thermocouple. Fortunately, adequate space was available for large diameter thermocouples, which have longer mean time to failure over smaller diameter thermocouples. Therefore, the decision was made to utilize $3.2 \mathrm{~mm}(0.125 \mathrm{inch})$ diameter type $\mathrm{N}$ 
thermocouples for AGC-1 and AGC-2. Thermocouple selection for the later experiments at higher temperatures, especially the $1200{ }^{\circ} \mathrm{C}$ experiments, are anticipated to include the INL developmental (molybdenum-niobium) thermocouples utilized in the AGR-1 irradiation. However the lower irradiation temperatures of AGC1 and AGC-2 were well within the range of commercial Type $\mathrm{N}$ thermocouples.

Data acquisition and archiving are also part of the control system function. Real time displays of all temperatures, gas mixtures, and alarm conditions are provided at the operator control station. All data are recorded once every minute, time stamped and archived to removable media. The control processor will record these values in a circular first-in, first-out format for a minimum of six months.

Monitoring the continuous sweep gas flow for various gases can provide valuable information on conditions inside the irradiation capsule. Examples include oxidation from trapped air/oxygen or possibly other gases being baked out of the graphite during the first few weeks of the irradiation. For this reason, the temperature control exhaust gas was routed past a sample station, after passing through a delay tank (to decay any activated argon Ar-41), before being sent to the ATR exhaust stack. Grab samples of the exhaust gas are analyzed on a gas chromatograph for various gases (e.g. $\mathrm{CO}, \mathrm{CO} 2$, etc.) with verification by a mass spectrometer in a laboratory located at the ATR Complex.

\section{III.B. Compressive Load Control System}

The compressive loads on the graphite specimens in the perimeter stacks are provided by the pneumatic rams located in the top of the test train away from the high radiation fields in the reactor core. A separate pneumatic ram is located above each perimeter specimen stack, and the forces exerted by the rams are controlled by a dedicated gas supply system. Each ram applies a downward force to a stainless steel push bar that transfers the force to a graphite push rod extending from above the top of the experiment capsule down to the top of the graphite stack. The force is then transmitted through the graphite specimens to a piston located at the vertical center of the ATR core. The piston sits on a ledge in the specimen holder to resist the force from the rams and therefore place the specimens under a compressive load. There is a space between the bottom of the ledge in the specimen holder and the top of the lower specimens to prevent the force/load from being applied to the lower specimens. The compressive loads applied to the specimens were 13.8 $\mathrm{MPa}(2,000 \mathrm{psi}), 17.2 \mathrm{MPa}(2,500 \mathrm{psi})$ and 20.7 $\mathrm{MPa}(3,000 \mathrm{psi})$. The same loads were applied to diametrically opposite pairs of specimen stacks in the capsule to prevent eccentric loads on the test train housing.

The force being applied to the specimens by the rams is monitored by load cells located between the rams and the push bars. In addition, the gas pressure being supplied to the rams is also monitored to provide a verification of the load cell readings. Position indicators are located above the capsule as far away from the high radiation fields as possible. The indicators monitor the relative movement of each push rod to measure the displacement of the graphite stack during reactor outages when the stacks are lifted upward a short distance. The upward lift of the specimens is accomplished using a series of gas bellows assemblies located at the bottom of the experiment capsule directly beneath each of the perimeter specimen stacks. The lifting operation is performed to ensure none of the specimens have become lodged in the specimen holder, which would prevent the compressive load from being applied equally to all specimens within the affected specimen stack. The gas bellows are operated using the same dedicated gas control system as the upper pneumatic rams. Helium is used for the working fluid in the compressive load system so any leaks would have a conservative (or cooling effect) on the graphite specimen temperatures. The control system components outside of the test train mainly consist of control and relief valves as well as pressure regulators. These components control and direct the helium supply gas to achieve the desired pressures in the pneumatic rams which in turn will provide the desired loads on the specimens. Signals from the load cells, position indicators and pressure transmitters are routed to the same distributed control system used to control the specimen temperatures. This system provides the appropriate alarm functions to notify the experiment operators when corrective actions are necessary.

\section{EXPERIMENT IRRADIATION RESULTS}

The irradiations of both AGC-1 and AGC-2 have been completed. The compressive load control system continued its excellent performance reported earlier in Reference 1, and the specimen stacks were successfully lifted during reactor outages throughout both irradiations using the lower gas bellows as outlined earlier. The temperature control system also continued to perform very well, and maintained 
constant and stable control of the experiment temperatures, though the actual temperatures were higher and their ranges greater than originally planned (see subsections IV.A and IV.B). Grab samples of the temperature control gas indicated minor oxidation of the specimens early in both irradiations. The oxidation resulted from oxygen trapped within the porous graphite specimens and other capsule components such as the graphite specimen holder, push rods and lower insulator. This oxygen was released (or baked out) from within the graphitic materials as the temperature of the experiments was increased to the design temperatures. However, the rate of oxidation, indicated by the concentrations of carbon monoxide and carbon dioxide in the temperature control exhaust gas, exponentially decreased to extremely low levels after the first week or two of irradiation and stayed there for the remainder of the irradiations.

The three most important parameters in the AGC irradiations are the fast neutron fluence (or damage), the specimen temperatures and the compressive loads imposed upon the creep specimens. There are, of course, a multitude of other irradiation parameters generated and archived during the irradiations, such as conductive and insulating gas flow rates, gas pressures in the temperature control and compressive load control systems, time etc. The preliminary results for these three parameters of both experiments are discussed in greater detail in the following subsections. These results are currently in different states of re-analysis, review and verification, so the final values may differ slightly from the ones reported here.

\section{IV.A. AGC-1 Preliminary Irradiation Results}

The mission of AGC-1 was to irradiate graphite at $600^{\circ} \mathrm{C}$ with various compressive loads to fast neutron damage levels of 3.5 to 6.0 displacements per atom (dpa). The preliminary estimates of the dpa levels achieved in the AGC-1 graphite specimens are shown in Figure 4 below. The colors/symbols for each specimen stack are shown at the top of the figure, which indicates a range of 1.4 to 6.9 dpa was achieved during the 351 effective full power days of irradiation. This spread envelopes the desired range of 3.5 to $6.0 \mathrm{dpa}$ and over $80 \%$ of the specimen stacks are contained within the desired 3.5 to 6.0 range. The fast neutron fluence spread between the specimen stacks had to be minimized in order to make the data as consistent and comparable as possible, especially between the specimen stacks under the same compressive loads. This was accomplished by rotating the experiments approximately halfway through their irradiation. As can be seen in Figure 4, the fast fluence distribution across all seven stacks was limited to 0.29 dpa out of 6.94 dpa or less than five percent.

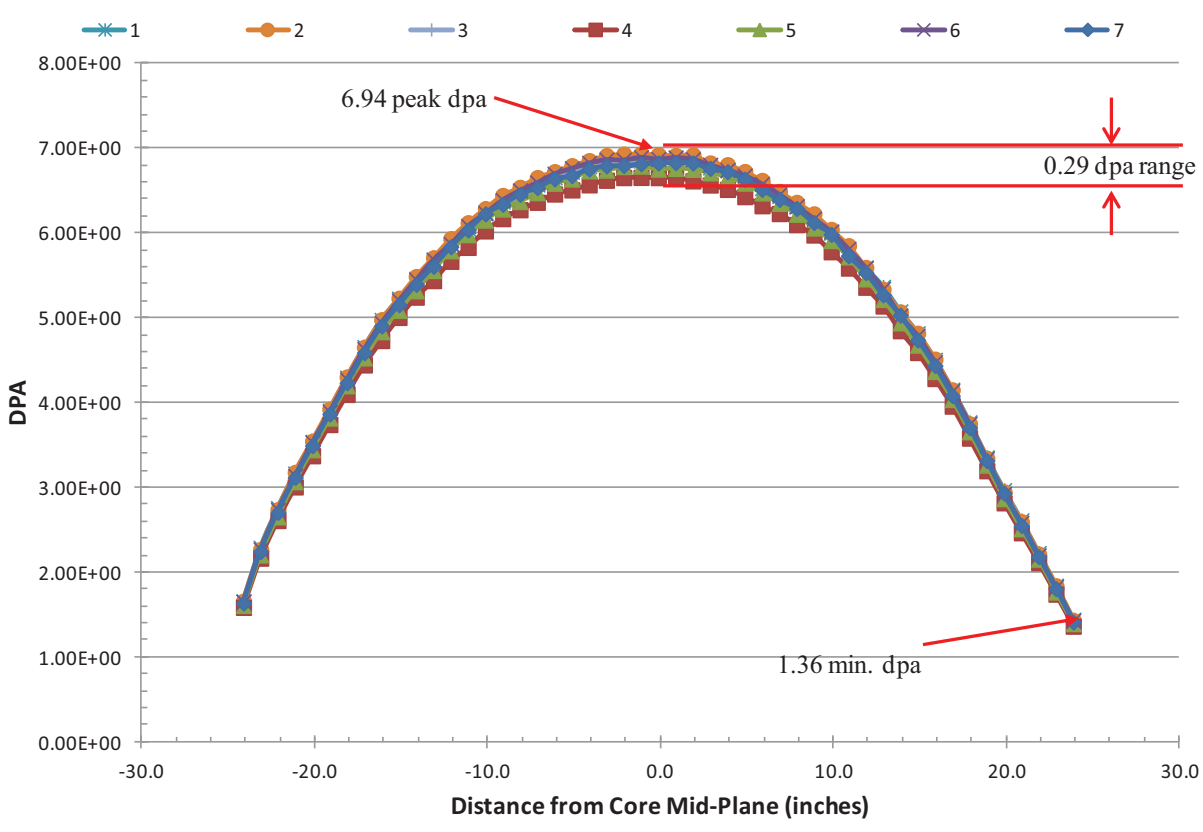

Fig. 4: Preliminary AGC-1 Fast Neutron Fluence Estimates 
The preliminary data for the compressive loads imposed on the upper half of the perimeter specimen stacks in AGC-1 are shown in Figure 5 below. The same compressive loads were applied to diametrically opposite stacks, which resulted in equal loads being applied to stack pairs of 1 and 4, 2 and 5 , and 3 and 6 . The areas on the figure indicating no loads being applied to the specimen stacks were due to reactor outages. The (very) slightly reduced loads shown in the first ATR irradiation cycle (145A) were due to initial system and experiment start-up checks being accomplished prior to imposing the full compressive loads. As shown in the figure and indicated earlier, the compressive load control system performed very well enabling the operators to maintain very constant loads on the specimens throughout the irradiation.

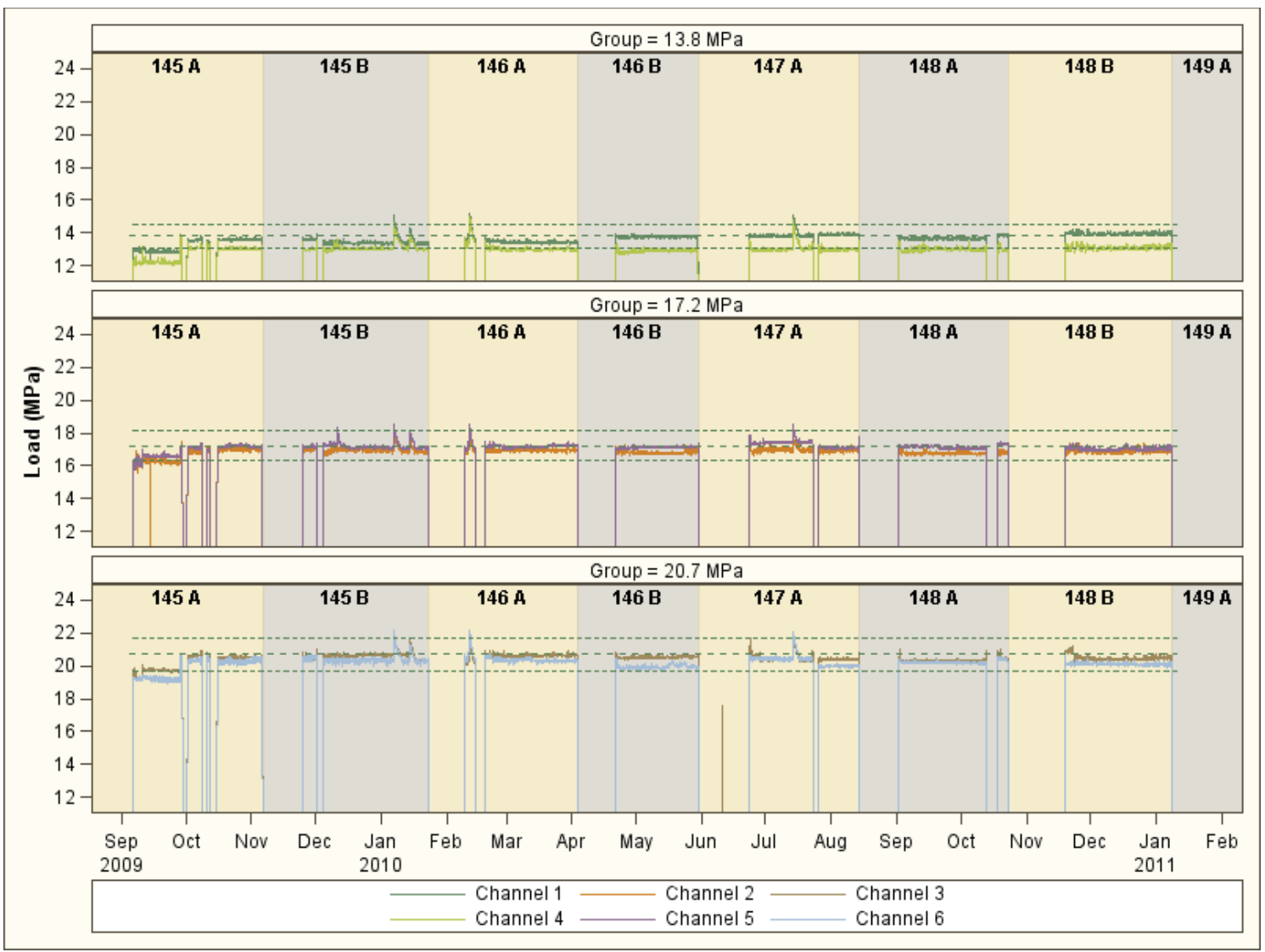

Fig. 5: Preliminary AGC-1 Compressive Load Data

The single (slight) exception to the otherwise great irradiation results of the AGC- 1 irradiation was the temperatures of the graphite specimens. The preliminary estimated temperature profile is shown in Figure 6. At the start of the irradiation, the peak specimen temperatures located at the vertical center of the ATR core were approximately $30^{\circ} \mathrm{C}$ over the desired design value of $600^{\circ} \mathrm{C}$ while flowing pure helium (e.g. conductive) gas. These temperatures easily met the design requirement for volume average specimen temperatures of $600 \pm 50{ }^{\circ} \mathrm{C}$. However, the specimens at the very top and bottom ends of the specimen stacks were being irradiated slightly below $500^{\circ} \mathrm{C}$ and $400^{\circ} \mathrm{C}$ respectively, which did not meet the desired minimum of $550^{\circ} \mathrm{C}$. Since the experiment was on pure helium (e.g. conductive) gas, it was recognized the specimen temperatures would continue to increase as the graphite thermal conductivity decreased from fast neutron irradiation damage. It was also recognized that it was much more important to maintain constant temperatures in the specimens than to necessarily achieve the original target temperatures. Therefore, the maximum specimen temperatures anticipated at the 
maximum fast neutron damage were estimated, and the strategy was adopted to mix argon (e.g. insulating) gas with the helium gas in the insulating gas gap to raise the specimen temperatures above these values along with a suitable margin early in the irradiation. This strategy provided the ability to reduce the argon gas ratio to compensate for the graphite thermal conductivity reduction and thereby maintain the temperatures as constant as possible throughout the irradiation.

In addition, the ATR neutron and gamma flux profiles are essentially symmetric about the vertical center of its core, which results in the compressively loaded and unloaded pairs in each of the six specimen stacks not only achieving very similar fast neutron fluences but also experiencing very similar temperatures through the irradiation. As can be seen in Figure 6, temperatures at points equal distances above and below the center of the ATR core are within approximately $50^{\circ} \mathrm{C}$ of each other. The preliminary reactor physics as-run analysis, which is performed utilizing actual reactor control data and fuel loadings for each reactor cycle, has been completed. The results of the as-run physics analysis are currently being used to perform an as-run thermal analysis that will more accurately establish the specimen temperatures during irradiation. These asrun analyses results will then be combined with the post irradiation examination of the specimens to establish the neutron damage and irradiation creep effects on the graphite material properties [2].

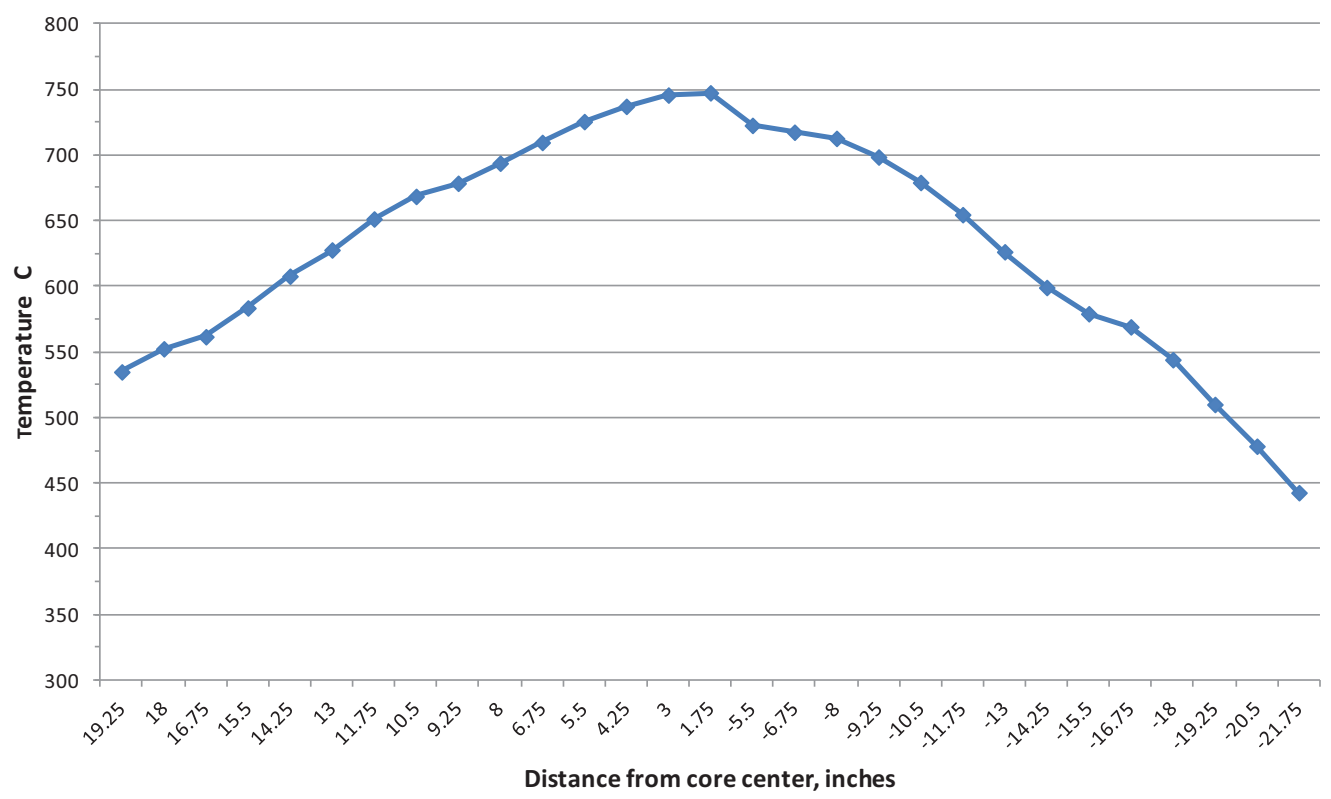

Preliminary AGC-1 Specimen Temperatures

Fig. 6:

\section{IV.B. AGC-2 Preliminary Irradiation Results}

The mission of the AGC-2 experiment was to irradiate graphite specimens at the same $600^{\circ} \mathrm{C}$ temperature and compressive loads as AGC- 1 but to lower fast neutron damage levels of approximately 1.0 to $4.5 \mathrm{dpa}$. This range was selected to provide data at lower dpa levels to supplement the data at higher levels from AGC-1 as well as provide overlap in the data from the two experiments. The preliminary estimates of the dpa levels achieved in the AGC-2 graphite specimens are shown in Figure 7. As can be seen in the figure, a range of fast neutron damage from 0.8 to $4.7 \mathrm{dpa}$ was achieved in the graphite specimens during the 240 effective full power day irradiation of AGC-2. The minimal distribution across the specimen stack peak dpa levels was accomplished (as in AGC-1) by rotating the experiment approximately halfway through its irradiation. The range of $0.18 \mathrm{dpa}$ across all seven stacks at a peak value of $4.66 \mathrm{dpa}$ amounts to less than four percent variation in peak dpa. 


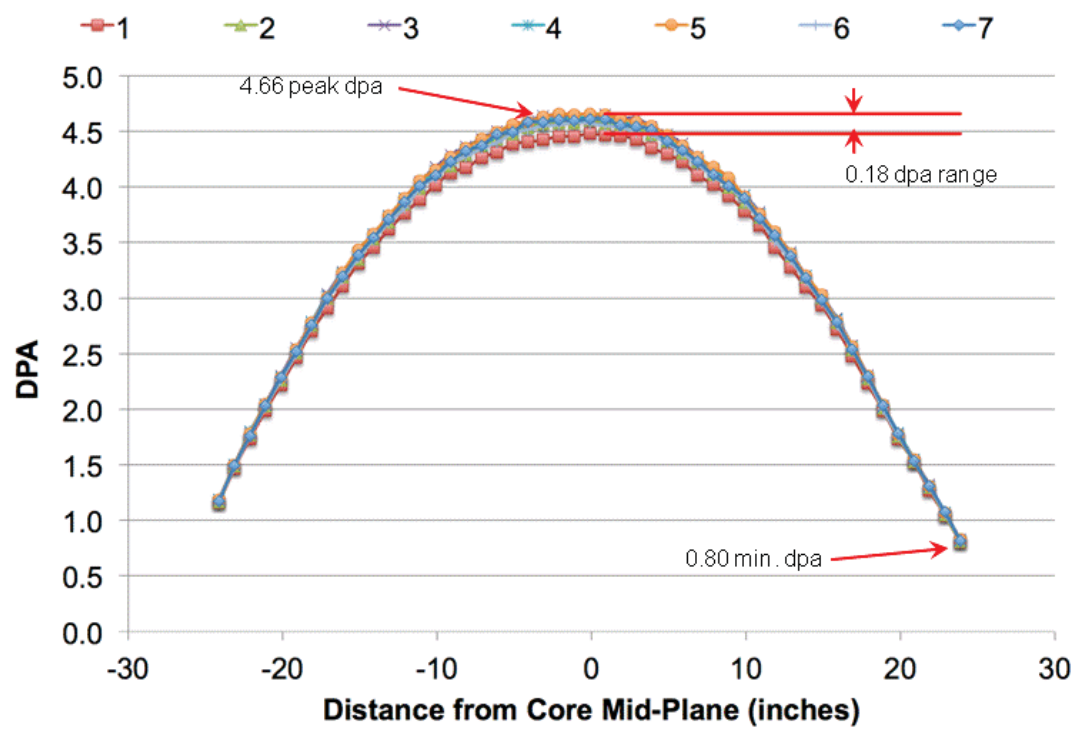

Fig. 7: Preliminary AGC-2 Fast Neutron Fluence Estimates

The preliminary data for the compressive loads imposed on the upper half of the perimeter specimen stacks in AGC-2 are shown in Figure 8. The same compressive loads were applied to diametrically opposite stacks as in AGC-1. Again, the areas on the figure where no loads are shown applied to the specimen stacks occurred during reactor outages. As noted earlier, the compressive load control system continued to perform very well with constant loads on the specimens throughout the irradiation.

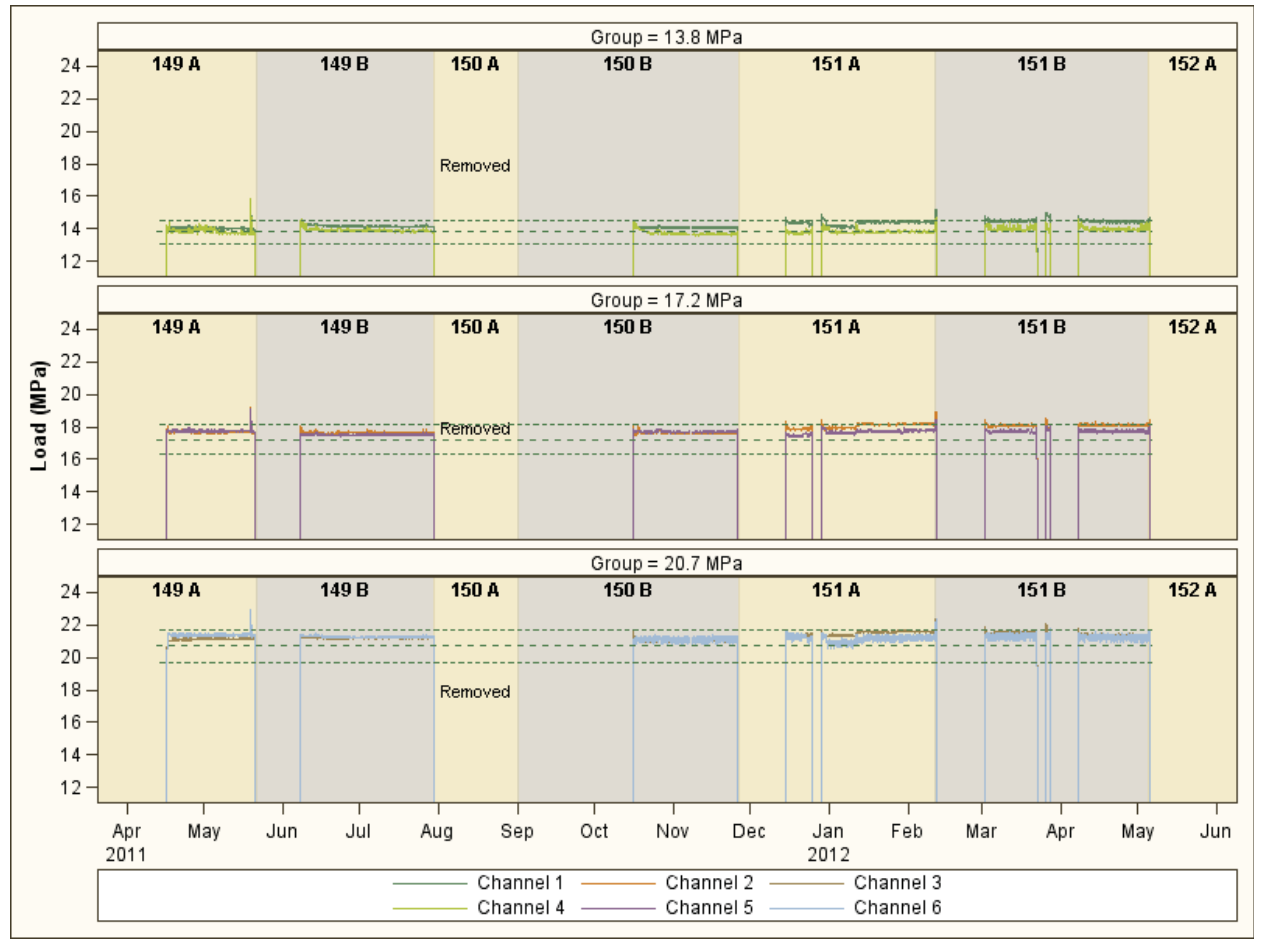

Fig. 8: Preliminary AGC-2 Compressive Load Data 
Since the irradiation has just very recently been completed (May 2012), there has not been adequate time to complete even the preliminary as-run thermal analysis. Therefore, the preliminary temperatures provided in Figure 9 are from the thermocouples recorded during the irradiation. Since the thermocouples are located in the specimen holder and not in the graphite specimens, the values shown will vary somewhat from the temperatures in the specimens. However, the trends will be the same and the relative magnitudes will be very similar.

This data shows the benefits of the design changes introduced in AGC-2 discussed earlier and detailed in Reference 1 . The significant reduction in the (axial) temperature distribution, shown by the temperature range across the four groups of thermocouples in figure 9, is a direct result of the gamma heaters added to the specimen stacks in
AGC-2. Other lessons learned from AGC-1, especially the error discovered in the thermal analysis software package, contributed to better controllability resulting in a more stable and consistent temperature profile in AGC-2 throughout its irradiation.

The initial temperatures shown below (cycle 149A) met the design requirements, but unfortunately, these temperatures were attained on almost pure conductive (helium) gas flow. There was concern that sufficient margin did not exist in the gas mixture to compensate for the anticipated graphite thermal conductivity changes caused by irradiation damage as discussed earlier in AGC-1. This issue coupled with the need to make the data between AGC-1 and AGC-2 as comparable as possible, resulted in the decision to increase the $\mathrm{AGC}-2$ irradiation temperature similar to that of AGC-1.

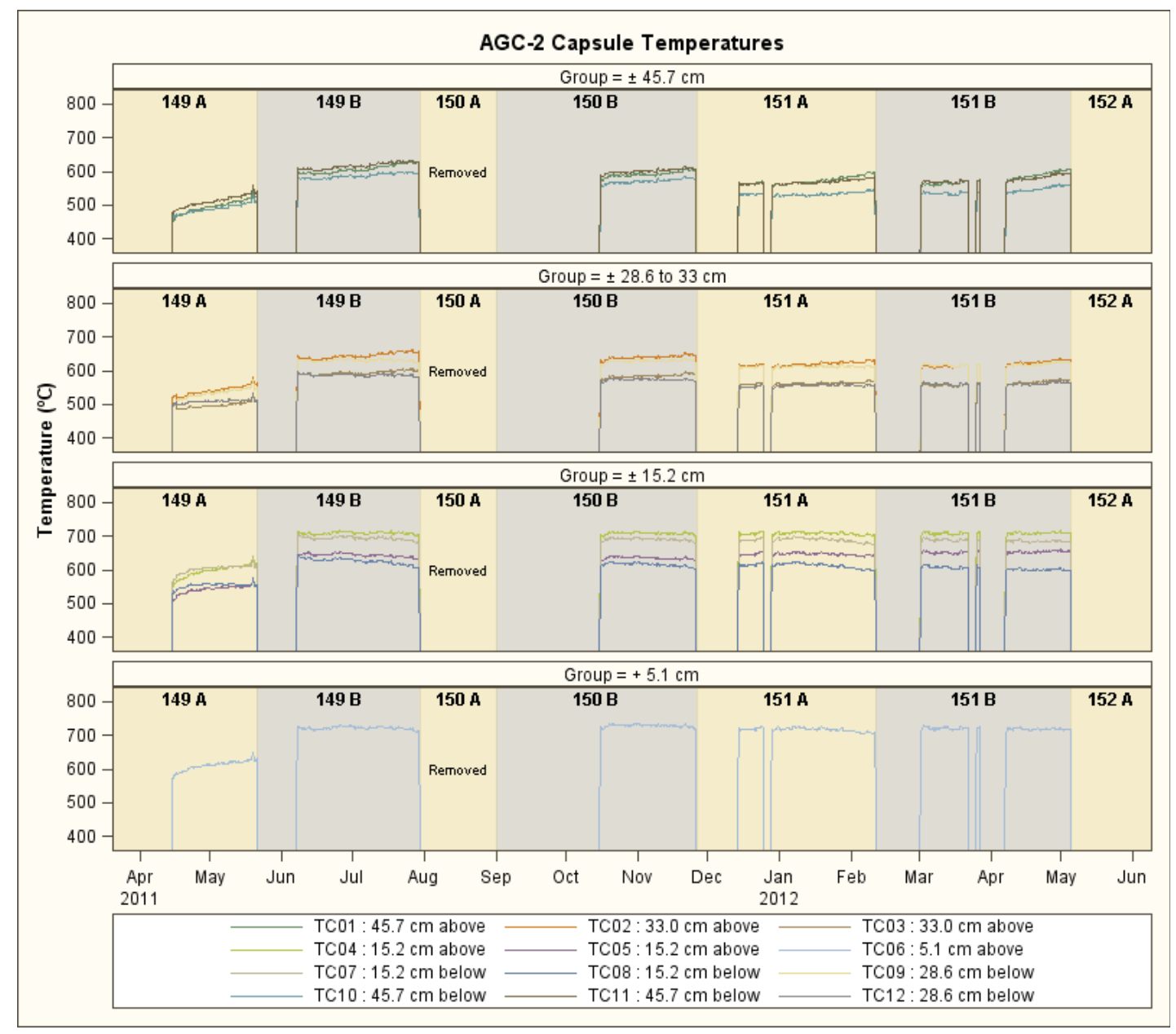

Fig. 9: Preliminary AGC-2 Temperature Data. 


\section{CONCLUSIONS}

Many valuable insights and lessons learned during the design, assembly and irradiation of AGC1 were applied to AGC-2 resulting in a significantly reduced axial temperature distribution and a much flatter temperature profile over the duration of the experiment. Lessons learned from both AGC-1 and AGC-2 have been incorporated into additional design changes for AGC-3 that show significant promise in attaining further improvements both in axial temperature distribution and experiment temperature controllability.

The results of the AGC graphite irradiations coupled with the pre-irradiation characterization and post irradiation examination of the graphite specimens will provide very valuable data on the irradiation behavior of the currently available nuclear grade graphites. This data can then be used in the future development and design of high temperature gas reactors.

\section{ACKNOWLEDGMENTS}

This work was supported by the United States Department of Energy (DOE) under DOE Idaho Field Office Contract Number DE-AC0705 ID 14517 .

\section{REFERENCES}

[1] S. B. Grover, The Next Generation Nuclear Plant Graphite Creep Experiment Irradiation in the Advanced Test Reactor, Proceedings of the Fifth International Conference on High Temperature Reactor Technology HTR 2010, Paper 105, Prague, Czech Republic, October 18-20, 2010

[2] W. Windes, Data Report on Post-Irradiation Dimensional Change in AGC-1 Samples, Idaho National Laboratory Report INL/EXT-12262555, June 2012. 